\title{
Retos del pensamiento crítico jurídico contemporáneo ante la complejidad de la racionalidad en la decisión judicial
}

\author{
Edwin Valladares \\ Universidad Centroamericana \\ "José Simeón Cañas", UCA
}

Resumen: El presente ensayo aborda algunos de los retos que el pensamiento crítico jurídico tiene en la actualidad, para constituirse en alternativa frente a las concepciones de derecho convencional. Nos referimos a una reflexión filosófica jurídica que, desde los aportes teóricos y normativos de la filosofía crítica, esclarezca alternativas que contribuyan a la toma de conciencia, al debate teórico-práctico, a la elección de nuevos criterios de interpretación y postura en la búsqueda de racionalidades que justifiquen decisiones jurídicas capaces de crear condiciones de factibilidad y posibilidad para la reproducción y desarrollo de la vida digna de todos y todas. Se trata, pues, de un esfuerzo académico destinado a recuperar el horizonte constitucional de la emancipación y dignificación del ser humano, quien, desde el enfoque humanista de nuestra Constitución, se configura en sujeto original y final de la actividad del Estado y, por ende, de la función judicial. ${ }^{1}$

Palabras claves: Derecho, pensamiento jurídico crítico, derecho convencional, decisión judicial, vida.

Abstract: The following article approaches the current challenges of critical legal thought, in order to build an alternative to the conventional law, i. e., a philosophical and legal reflections in order to give elements for legal decisions that creates conditions for a dignified life for every person. It is an academic effort in order to retrieve the constitutional horizon of emancipation and dignification of human being, who is the main subject of the activity of the State and thus of the legal function

Keywords:Law, critical legal thought, conventional law, legal decision, life. 


\section{Diagnóstico general del problema abordado}

El pensamiento crítico jurídico es, sin duda, una concepción del derecho necesaria para cualquier sistema jurídico del orbe, más allá del modelo de constitucionalismo que se adopte. No obstante, hoy en día, la reflexión jurídica alternativa en el ámbito académico y la praxis forense es escasa, al no entenderse a cabalidad la trascendencia de lo que ella significa e implica para la protección de los derechos fundamentales, olvidando casi siempre que la praxis forense debe fijar a la persona humana (corporal, necesitada y vulnerada) como origen y fin de la decisión judicial, es decir, que la persona humana y sus derechos es el fundamento primario y legitimador de la función judicial.

En efecto, se aduce por sus críticos que el pensamiento crítico jurídico es escéptico e inviable en la praxis forense, pues reduce el derecho a un instrumento de poder, una reflexión sociológica del derecho, una ideología. También se aduce que la dogmática jurídica se convierte en una actividad política; se da poca importancia al conocimiento del derecho válido y vigente aplicado por los tribunales. Además, las esperanzas que se depositan en la capacidad de la dogmática jurídica para cambiar el derecho son excesivas. Por último, se configura la ciencia jurídica como una segunda instancia democrática
2. Sin embargo, si asumimos la tesis de que el derecho es una práctica social, éste no debe ser ajeno a los valores de esa práctica social. Más allá de la dimensión normativa y técnica del derecho se encuentran las dimensiones, sociales, económicas, políticas, históricas, culturales, y antropológicas, que exigen que el derecho cumpla una función mediadora para reproducir y desarrollar la vida digna.

Frente a este escenario, las interrogantes clave a formularnos son: ¿Cuál es la importancia que tiene el pensamiento crítico jurídico frente al impacto negativo que la globalización económica provoca sobre el contenido de los derechos fundamentales de la vida? ¿Qué presupuestos teóricos y prácticos debería asumir el pensamiento crítico jurídico para ponerse a la altura de los avances que han experimentado en los últimos años las concepciones de derecho convencional? ¿Constituye el pensamiento crítico jurídico una concepción de derecho alternativa frente a las concepciones de derecho convencional? ¿Qué tipos de racionalidad jurídica debería asumir el pensamiento crítico jurídico para que la decisión judicial dé cuenta de los derechos fundamentales de la vida? ${ }^{3}$ Para hallar respuestas fiables, debemos comenzar a desentrañar este enigma, partiendo de un diagnóstico situacional, provisional, 
histórico, claro y objetivo, realizando luego algunas consideraciones académicas y prácticas pertinentes que nos ubiquen mejor y nos permitan luego plantear algunas propuestas viables de solución.

Pues bien, nos encontramos a las puertas de la tercera década del siglo XXI, y algunas de las críticas formuladas por el pensamiento crítico jurídico a las concepciones de Derecho convencional fueron superadas, al menos, teóricamente y por alguna praxis forense; de igual modo, algunas críticas formuladas por las concepciones de Derecho convencional al primero están teóricamente superadas. Sin embargo, aún persisten críticas relevantes y pertinentes a las concepciones del Derecho convencional. Cinco son de capital importancia porque nos permiten efectuar un diagnóstico claro y objetivo del tipo de problemas con los que los teóricos críticos y operadores del derecho suelen lidiar en la cotidianidad.

\section{A. El señalamiento de que el pensa-} miento crítico jurídico no es una concepción de derecho. Vale decir, que si bien es cierto, es poco conocido en nuestro medio, pero en algunos países suramericanos puja por instalarse como un modelo alternativo en un escenario dominado por el positivismo normativo, el iusnaturalismo, post positivismo y neoconstitucionalismo; lo cual, es una pretensión absolutamente válida y además saludable para el campo de la filosofía del derecho, dogmática jurídica y la praxis forense, pues el pensamiento crítico jurídico, entendido en sentido estricto, trae al debate jurídico cuestiones y aspectos que han sido descuidadas por los teóricos y operadores del derecho ${ }^{4}$; además, su interés en superar los obstáculos epistemológicos (Cárcova, 2009, p. 8$)^{5}$ de las concepciones de derecho convencional, lo lleva hacia la búsqueda de ciertas rupturas con la teoría y praxis forense dominante; por último, lleva al análisis exhaustivo del proceso de constitucionalización de los derechos fundamentales y la organización del poder político, a fin de instalar el debate serio sobre la presencia permanente del poder constituyente.

B. La teoría jurídica convencional, por medio del conocimiento-regulación, absorbió el conocimiento-emancipación del derecho. Todo pensamiento jurídico, para que sea crítico, debe tener como objetivo primario y final la dignificación y emancipación del sujeto frente a las leyes injustas y las instituciones públicas y privadas que lo oprimen, explotan o excluyen socialmente. Esta idea regulativa del derecho dentro del paradigma de la modernidad se mueve entre la tensión del conocimientoemancipación y el conocimiento- 
regulación, con el fin de articularse en un equilibrio dinámico de la solidaridad, justicia, igualdad, libertad y autonomía, de los seres humanos, pero al ser confiado este equilibrio a la racionalidad cognitivo-instrumental de la ciencia jurídica, dio prioridad al conocimiento-regulación que recodificó bajo sus propios términos el conocimiento-emancipación y redujo drásticamente las promesas y posibilidades de liberación y dignificación del sujeto de derecho, es decir, la regulación jurídica absorbió en sí el potencial emancipador del nuevo paradigma jurídico."Esta es la situación en la que nos encontramos y de la que urge salir. El camino no puede ser sino la reevaluación del conocimientoemancipación, concediéndole la primacía sobre el conocimientoregulación" (Santos, 2003, pp. 86-87) ${ }^{6}$.

C. El impacto de la estrategia de globalización capitalista en la esfera de los derechos sociales. Este impacto es negativo, al punto, que deja sin efecto los logros anteriores en materia de salud, trabajo, educación, alimentación -y hace imposible volver a recuperarlos, pues, fueron sustituidos por la absolutización de los derechos de las empresas (Hinkelammert, 2003, p. 23) ${ }^{7}$, que en la praxis se traducen como los derechos garantizados plena- mente. Eduardo Faría, cuando analiza la crisis actual del Estado social de derecho, afirma que, con la transnacionalización de los mercados, la consiguiente desterritorialización de la producción, los nuevos esquemas regulativos y las nuevas formas organizativas e institucionales supranacionales, está aconteciendo un creciente vaciamiento de la fuerza normativas de los textos constitucionales (Faria, 2001, p. 29). En la misma línea, Ferrajoli, cuando reflexiona sobre la crisis de los derechos fundamentales, sostiene que: "La actual crisis de la democracia en todas sus formas y dimensiones consiste en la impotencia de la política frente a los desafíos globales y en su omnipotencia en relación con los sujetos más débiles" (Ferrajoli, 2014, pp. 169-170). Frente a esta realidad negativa, es necesario y urgente que los operadores del derecho al momento de justificar las decisiones judiciales apliquen en su ejercicio mental varios tipos de racionalidades ${ }^{8}$, con el fin de transformar en sentido positivo estas realidades.

D. La colonización del derecho. La mayoría de países latinoamericanos no tienen una cultura jurídica propia, si bien es cierto, a finales del siglo XIX se independizaron de la colonización española y portuguesa, realizaron una recepción acrítica del derecho 
europeo continental, representada por las fuentes clásicas del derecho romano, germano y canónico, en el que gradualmente, se adaptaron y se destacaron principios del ideario económico capitalista, de la doctrina del liberalismo individualista y de la filosofía positivista. Como bien señala Wolkmer: "la incorporación del modo de producción capitalista y la inserción del liberalismo individualista tuvieron una función importante en el proceso de positivación del derecho estatal y en el desarrollo del derecho privado (con énfasis en el derecho de propiedad y en el derecho mercantil" (Wolkmer, 2006, p. 102). Esta tónica persiste hasta nuestros días, ya que la racionalidad legislativa no está pensada desde las propias circunstancias socio-históricas de América Latina, o desde la lucha por la dignidad humana, sino que, sobre todo, responde a estímulos inmediatistas, intereses de sus patrocinadores o las presiones de organismos multilaterales. De ahí que uno de los retos que tiene el pensamiento crítico jurídico contemporáneo es la descolonización del derecho, como veremos adelante.

E. La teoría jurídica convencional suplanta al sujeto concreto de derecho por un sujeto abstracto. Desde esta inversión ideológica, la teoría y praxis forense provocan efectos indirectos para el desarrollo de la vida digna y, por ende, menoscaban la dignidad y derechos de la persona humana. En efecto, esta inversión imposibilita el "acuerdo" libre y espontáneo entre sujetos autónomos, al punto que, si no se toma en cuenta en la fundamentación de la sentencia judicial la condición necesitada y vulnerable del sujeto, no solo se oculta y elude las desigualdades, sino que también se impide que la desigualdad y el conflicto, se trasladen al ámbito político del derecho. Por tanto, es necesario construir un aparato crítico jurídico que nos permita mostrar que la inversión ideológica del sujeto concreto de derecho a "sujeto incorpóreo presente en teorías del derecho convencional $\mathrm{y}$ en los derechos humanos, cuyo legalismo se expresa en el desprecio del ser humano en tanto viviente concreto, se opone a una concepción comunitaria de lo corporal" (Molina, 2006, p. 24) y exalta un formalismo abstracto.

Desde luego que al diagnóstico general realizado pueden añadirse un sin número de causas y efectos perniciosos que inevitablemente inciden en la racionalidad de la decisión judicial; no obstante, con lo anotado queda ya establecida la problemática ética-jurídica que 
oprime y excluye el sujeto concreto de derecho, a pesar de los avances que los últimos tiempos han experimentado las concepciones más representativas de derecho convencional.

\section{Retos del pensamiento crítico jurídico contemporáneo}

Nuestra pretensión en este apartado consiste en elaborar unas líneas generales del pensamiento crítico jurídico y, a partir de ellas, señalar algunos retos que, en nuestra opinión, tiene esta concepción del derecho para crear una teoría de la argumentación jurídica que posibilite a los jueces justificar una decisión judicial sostenible en el Estado constitucional y democrático de Derecho. Pues, como se sabe, esta corriente de pensamiento jurídico se opone al determinismo de los comportamientos y al mecanicismo. Igual, se opone, a todo positivismo (instalado en el statu quo) y abre la posibilidad crítica a la negación de lo existente y, por tanto, al pensamiento antisistema y, al pensamiento utópico entendido como meta.

Esta pretensión de dar otra mirada al sistema jurídico-político propuesto por el poder constituyente, tiene como limitantes la ambigüedad, elasticidad y amplitud del término crítica; asimismo, los innumerables significados con que el mismo se ha empleado a través del tiempo, entre ellos podemos mencionar el erecho alternativo, los Critical Legal Studies, el Nuevo Constitucionalismo Latinoamericano, entre otros. A esto hay que agregar la confluencia de diversas teorías críticas jurídicas de las que parten sus actores más representativos. Por tanto, se debe tener sumo cuidado a la hora de reducir el pensamiento crítico jurídico a la teoría marxista, y peor aún, al marxismo ortodoxo.

Llegado a este punto del análisis, es necesario hacer una distinción entre lo que suele llamarse teoría crítica en sentido amplio y en sentido restringido. En sentido amplio, es todo aporte discursivo que refiere a toda a toda disidencia o innovación que ponga en cuestión algún aspecto del statu quo teórico, en un área determinada del derecho. Por el contrario, desde el punto de vista estricto sólo podrá entenderse por teorías críticas del derecho, aquellas que en general guardan correspondencia discursiva y conceptual con la tradición filosófica que se concreta en el siglo XX en la Escuela de Frankfurt. Esta encuentra su aspiración teórica en la tradición que se remonta lejanamente a la dialéctica hegeliana, el pensamiento de Nietzsche, al subjetivismo psicoanalítico freudiano, a la sociología weberiana, culminando con un fuerte intento de la reformulación del materialismo marxista, y luego continúa hasta 
nuestros días con los aportes de sus epígonos intelectuales y otras contribuciones filosóficas que conforman un núcleo teórico, aunque sea parcialmente afín (Meliante Garcé, 2014).

Ahora bien, tomando en cuenta lo complejo que resulta justificar la decisión judicial, nos vamos a decantar por las teorías jurídicas en sentido estricto, pues nuestro interés radica en reflexionar sobre las relaciones entre derecholenguaje, derecho-poder, derechopolítica, derecho-ideología, derechonarrativa, derecho-decisión judicial, derecho-interdisciplinariedad, además de la sabida reformulación del concepto de sujeto concreto de derecho. Se trata de categorías que en la actualidad no tienen atención seria por parte de los juristas teóricos y prácticos.

De lo anterior se colige, que actualmente el pensamiento crítico no es un corpus monolítico o una sola visión sino una heterogeneidad de posiciones que intenta construirse sobre una base epistémica diferente a la "moderna" (compleja, postcolonial, transmoderna, puede haber otros nombres), que es la que comparten el positivismo (al menos, el hegemónico) y el iusnaturalismo (versión racionalista particularmente). $Y$ consideramos que es necesario discernir esto para evidenciar que en el pensamiento crítico jurídico no existe un intento de reconciliación con estas corrientes de pensamiento jurídico, sino un intento de superación. Pues, al menos desde el enfoque que asumimos, intenta "dialogar", discernir, y en lo que competa "recuperar reubicando las cosas" o superarlas si fuera meritorio.

En este intento de diálogo con las concepciones de derecho convencional, el pensamiento crítico jurídico asume el postulado básico del positivismo en el sentido de que el derecho es derecho "puesto", es decir, derecho producido sociohistóricamente. En ese sentido no es iusnaturalista. Pero puede compaginar con el iusnaturalismo un ámbito aspiracional, que en el caso del pensamiento crítico se entiende desde la perspectiva de la utopía, no de ninguna supuesta "naturaleza" humana. La utopía es contrafáctica, sirve para elucidar y denunciar "lo que es", y orienta para construir algo nuevo, pero sin pretender hacer "lo que no es" (utopía), de ahí que, en términos hinkelammertianos, no hay acercamiento asintótico entre utopía y realización sociohistórica.

\section{El pensamiento crítico sí enfrenta} el proceso de anquilosamiento 0 hipertrofia del positivismo, que se expresa en el normativismo formalista, en el procedimiento absoluto y el imperialismo moral. Estas derivas se dan por un proceso de sacralización del derecho positivo, que lo saca de su contexto 
de producción y realización y lo erige en (pretendidamente) "absoluto".

Del iusnaturalismo retoma y reubica la potencia "rebelde", derecho a la insurgencia, a la "desobediencia", pero exige argumento que está dado por un juicio contextual y consecuencial (no se trata de ningún fundamento esencialista o sobrehumano), es decir, las cosas se valoran por sus consecuencias, que en términos categoriales están dados por los extremos vida-muerte. Vale aclarar, que el derecho a la desobediencia no significa per se la destrucción del orden jurídico existente, sino la exigibilidad que el derecho válido y vigente se ponga en función de la vida a la cual pretende servir.

Con esto quiero señalar que el pensamiento crítico jurídico no está condenado sólo a señalar las insuficiencias del positivismo, sino que él mismo, en su apuesta y contingencia, es un intento de construcción, eso sí, a cuenta de ser radicales y coherentes, se trata de una construcción sometida al escrutinio constante, a la revisión permanente, incluso para cuestionarla y superarla (esta es, con mucho, la mayor dificultad para aceptar y asumir la posición crítica).

Tomando en cuenta las ideas presentadas en este apartado y la crisis que la actual estrategia capitalista de globalización económica provoca para la interpretación y aplicación razonable de los derechos fundamentales, consideramos que el pensamiento crítico jurídico contemporáneo tiene muchos retos por cumplir, pero por espacio limitado de este trabajo, solamente vamos a señalar cinco, que a nuestro juicio son urgentes y necesario para justificar la decisión judicial.

A. El reto básico es identificar y contribuir a configurar un sujeto concreto de derecho, el cual para que sea tal debe ser alternativamente un sujeto vivo, intersubjetivo, plural, dialogante, solidario, práxico, libre, integrador de las diferencias $^{10}$, descolonizador, trascendente y recuperador de planteamientos epistemológicos alternativos.

B. Ser un pensamiento racional, con una característica muy específica: producir "el desbloqueo de la razón jurídica" (Cabo Martín, 2014, p. 54), presa del Derecho convencional con todas sus implicaciones. Esto pasa por introducir al debate jurídico el criterio vida o muerte en el que se mueven las decisiones judiciales, a fin de mostrar a la comunidad jurídica y comunidad política que no se deben tomar como racionales resoluciones que provocan muerte en nombre de la razón jurídica. 
C. Construir una dogmática que no sea estrictamente endógena, intrasistema, como es la que construye a partir de un determinado entendimiento del derecho que, a través de la "pureza metódica" y "construcciones lógicas", la convierten en técnicamente indiscutible y, finalmente, neutral o con escasa capacidad crítica. Porque, aunque en el proceso argumentativo se trate de "valores", son siempre los positivados y, por tanto, es muy difícil que la construcción dogmática (aunque siempre caben diferencias) sea contradictoria (Cabo Martín, 2014, p. 54).

D. Mostrar que descolonizar el derecho no significa renunciar a los aportes que nos hereda el humanismo jurídico, las teorías de argumentación jurídica, el paradigma constitucionalista, y la hermenéutica jurídica con sus principios de proporcionalidad y ponderación, sino que significa "apartarse de los trasplantes - injertos constitucionales eurocéntricos, para aprovechar el momento de firme actividad constituyente, repensar siquiera brevemente y con las limitaciones del momento político sobre la situación y buscar aquellas medidas que pudieran dar solución a sus problemas particulares" (Martínez Dalmau y Viciano Pastor, 2011). Por último, descolonizar no significa renunciar al diálogo con otras culturas jurídicas. El pensamiento crítico jurídico debe continuar siendo intercultural.

E. Matizar sus postulados básicos sobre las fuentes del derecho, el vínculo entre derecho y moral, y la discrecionalidad judicial. Asimismo, elaborar una teoría de argumentación jurídica que tenga en cuenta el tipo de razonamiento que tiene lugar en el contexto de la resolución de conflictos y, otra teoría, de la interpretación del derecho que tenga en cuenta una concepción alternativa del derecho, pues en nuestra opinión, se cuenta con los insumos teóricos y prácticos pertinentes para asumir este reto.

\section{El paradigma de las nuevas concepciones de derecho y su impacto en la justificación de la decisión judicial}

Para los efectos de este apartado vamos a definir tres conceptos elementales: Derecho convencional, las concepciones de derecho, y las corrientes del pensamiento jurídico. Llamo derecho convencional a aquellas concepciones de derecho en las que los juristas prácticos, 
para interpretar y aplicar la ley, niegan, como tema central de su reflexión, que el sujeto de derecho sea alternamente un sujeto vivo, intersubjetivo y práxico; a contrario sensu, se apoyan en formulaciones abstractas del sujeto de derecho, en visiones monoculturales del derecho (inglesa, francesa y estadounidense), y en un derecho formal que sin tomar en cuenta el tipo de relaciones sociales y el tipo de relaciones de fuerza en las que se ve inmerso el sujeto de derecho, pretende lograr la compatibilidad entre derechos de naturaleza distinta (derechos del propietario con los derechos vitales); por tanto, su función práctica es limitada para proteger, defender los derechos fundamentales, y construir una sociedad donde todos quepan.

Con relación a las concepciones de derecho, Manuel Atienza señala lo siguiente: "Una concepción del derecho viene a ser un conjunto de respuestas, con cierto grado de articulación entre sí, a una serie de cuestiones fundamentales en relación con el derecho: cuáles son sus componentes básicos, como se determina el derecho válido, qué relación mantiene con la moral o la política, en qué consisten las operaciones de interpretarlos y aplicarlo, etc." (Atienza, 2013, p. 21). Por último, respecto, a las corrientes de pensamiento jurídico, la Sala de lo Constitucional de nuestro país en la Referencia 78-2011 pronunciada sentencia Definitiva a las $12 \mathrm{hs}$. del $1^{\circ}$ de marzo de 2013, argumenta que "aluden precisamente a visiones, teorías o concepciones del derecho, es decir, a los sistemas de pensamiento, visión del mundo o conjunto de ideas del magistrado sobre el papel del derecho en la sociedad, su relación con el poder, la moral y los valores, así como el método jurídico y la función de los jueces en el cumplimiento de las prescripciones jurídicas que integran el ordenamiento". Aparentemente, entre estos conceptos existe una diferencia de género y especie, pero su análisis desbordaría los objetivos de este trabajo, por lo que no vamos a detenernos en ello.

Llegado a este punto del análisis, se debe reconocer los avances que han experimentado las concepciones de Derecho convencional en los últimos tiempos en materia de interpretación y aplicación de la ley. En esta medida, ya no cabe la crítica formulada por el pensamiento crítico jurídico al formalismo jurídico ${ }^{11}$ sobre la interpretación mecánica para la aplicar la ley, tampoco cabe la crítica formulada al positivismo jurídico ${ }^{12}$ sobre la separación entre derecho y moral. Así pues, la aplicación de la lógica formal en el razonamiento jurídico como recurso suficiente para determinar el contenido de la ley o en su caso la ausencia del referente moral para determinar el contenido de los principios constitucionales, es cuestión del pasado. Efectivamente, con la puesta en práctica del 
paradigma del Estado constitucional de derecho, el formalismo jurídico y el positivismo normativo entraron en una crisis irreversible sus postulados básicos: la separación entre derecho y moral y la discrecionalidad judicial. Estos fueron sustituidos por los postulados de la relación entre derecho y moral, y la discrecionalidad judicial atenuada por la vía de la justificación de las resoluciones ${ }^{13}$ .En suma, la transformación del Estado de Derecho, en su fórmula de Estado legal de Derecho al Estado constitucional de Derecho puso en crisis el paradigma positivista y marcó el tránsito hacia el paradigma postpostivista.

Se piensa que los únicos responsables de la crisis de las concepciones de derecho antes mencionada son el neoconstitucionalismo ${ }^{14}$ y el postpositivismo, aunque nosotros pensamos que en cierta medida también lo es la teoría crítica jurídica, que incluso podríamos llamarla postpositivismo crítico. Pero, para ser congruentes con el tema sólo revisaremos puntualmente el neoconstitucionalismo y el postpositivismo. Respecto al primero, se suele afirmar que surge en Europa después de la segunda guerra mundial como una respuesta a sistemas jurídicos fascistas que se caracterizaron por la violación masiva y sistemática de los derechos humanos.
Las propuestas e innovaciones del neoconstitucionalismo son: (1) Ampliación del catálogo de derechos fundamentales; (2) Rigidez en el procedimiento de reforma constitucional; (3) Carácter normativo o fuerza vinculante, en el que la Constitución como norma jurídica es aplicable directamente; (4) El control de constitucionalidad de la actividad del Estado y de los particulares que se encuentran en posición de poder frente a los ciudadanos; (5) Garantía judicial para la protección o tutela de los derechos fundamentales y; (6) la creación de Cortes o Tribunales Constitucionales como órganos independientes de los poderes clásicos del Estado.

A partir de estas propuestas e innovaciones, el impacto que el neoconstitucionalismo tiene para la justificación de la decisión judicial también deriva del método empleado en la aproximación al Derecho, y la relación que asume entre derecho y moral. En efecto, esta concepción de Derecho suma a los métodos tradicionales de interpretación de la ley el criterio de proporcionalidad, la ponderación y el método teleológico. Respecto al vínculo que éste atribuye al derecho y la moral, considera que la Constitución encarna una síntesis entre derecho y moral, es decir, los derechos fundamentales son valores morales consensuados, esos valores son ya normas positivas. La consecuencia es que las normas fundamentales deben dotarse de 
contenido, siguiendo la filosofía de la Constitución.

Como vemos, estamos en presencia de un nuevo paradigma en cuanto a la forma de comprender y aplicar el derecho. El responsable de ello es un constitucionalismo que ha modificado la manera de entender el derecho,llevando a situar en un primer plano la dimensión argumentativa e interpretativa del derecho. Con relación a esta dimensión, destaca el hecho de que los principios al igual que los reglas son normas objeto de interpretación y aplicación, pero la importancia radica en el hecho de que los principios a diferencias de las reglas, no basta para su interpretación la estructura lógica formal del razonamiento, sino que, además es necesario para determinar su contenido, la aplicación de un razonamiento práctico que incorpore relaciones de justificación. Ligado a ello, la validez pasa a ser entendida en términos sustantivos y no meramente formales: para que sea válida, una norma debe respetar los principios y derechos establecidos en la Constitución (Lifante, 2008).

No cabe duda, que el paradigma constitucionalista ha marcado la tendencia hacia la integración entre las diversas esferas de la razón práctica: el derecho, la moral y la política. Esto implica que tal paradigma no es descontextualizado, deshistorizado, dogmático, ni cerrado; por el contrario, es histórico, contextualizado, provisional y flexible, orientado hacia el logro de objetivos sociales y la incorporación de todos aquellos valores morales posibles de fundamentar racionalmente desde la filosofía constitucional. Como consecuencia de esto, la función judicial, ahora guiada por una idea de corrección y pretensión de justicia, combina la razón instrumental y la razón práctica para evaluar los medios que conducen a la consecución de fines constitucionales.

Frente a las exigencias del nuevo paradigma constitucional de justificar racionalmente las decisiones judiciales, y la necesidad de asumir la tesis del derecho como práctica social, una práctica consistente generalmente en argumentar. El neoconstitucionalismo asumió nuevos métodos de interpretación del derecho entre ellos: el principio de proporcionalidad y la ponderación, a fin de asumir una visión de la interpretación como una actividad reconstructiva, y no como una mera precisión del significado de las palabras de una determinada disposición legislativa (Lifante, 2008, p. 269). Ahora bien, si la naturaleza de la actividad interpretativa es la de ser una actividad argumentativa, creo que bajo estos métodos de interpretación se pueden tutelar 
de mejor modo los valores y fines constitucionales.

En cuanto a la aplicación del principio de proporcionalidad por el neoconstitucionalismo y su abandono del puro esquema lógico-deductivo para argumentar y justificar la decisión judicial, Jaime Cárdenas Gracia sostiene: "No basta ya acudir a razones exclusivamente formales -competencia del órgano y procedimiento-, sino debe acudirse a contenidos, fines y valores" (Cárdenas, 2007, p. 41). Indudablemente, esto provoca un impacto positivo en la decisión judicial, ya que el principio de proporcionalidad, al descomponerse en otros subprincipios como idoneidad, necesidad y proporcionalidad en sentido estricto, posibilita al jurista práctico "acreditar la adecuación, aptitud o idoneidad de la medida objeto de enjuiciamiento en orden a la protección o consecución de la finalidad expresada; esto que la actuación afecte a un principio o derecho constitucional" (Alexy, 2018, p. 200).

Algo similar ocurre con el principio de ponderación, el cual se encuentra dentro de la proporcionalidad. La ponderación es necesaria por varias razones, pero aquí sólo nos vamos a referir a la posibilidad de conflictos entre principios. En cuanto a la ponderación como herramienta necesaria para justificar la decisión judicial, requiere que los juristas prácticos tomen en cuenta su estructura, la cual, según Bernal Pulido, está formada por tres elementos: la ley de ponderación, la fórmula del peso y las cargas de argumentación.

Mediante el primer elemento de la estructura los operadores del derecho deben procurar que el grado de satisfacción de los principios en conflicto sea mayor, y en caso de afectación de un principio sobre otro moverse en la argumentación de la decisión dentro de la escala "leve", "medio", o "intenso", a fin de justificar la afectación o no satisfacción de un principio. La fórmula del peso se debe medir en atención a cada caso concreto y en función al peso que un derecho tiene frente a otro para satisfacer la libertad, la igualdad, la vida digna del ser humano. Por último, las cargas de argumentación operan cuando existe un empate entre los valores que resultan de la aplicación de la fórmula del peso, es decir, cuando los pesos de los principios en conflicto son idénticos, por ejemplo, igualdad jurídica y libertad jurídica (Bernal Pulido, 1998). Optar por uno de ellos llevará al operador del derecho a dar razones de peso para que la decisión judicial encuentre legitimación en una sociedad democrática

Respecto al postpositivismo, vale decir que para Manuel Atienza la crisis de concepciones de derecho, tales como el formalismo jurídico, 
el positivismo normativista, el realismo jurídico, iusnaturalismo y el escepticismo jurídico, se debe a la irrupción en las últimas décadas del siglo $X X$, del paradigma del constitucionalismo. Con relación a lo que se debe entender por paradigma constitucional nos vamos a ceñir a lo que se dijo anteriormente. Por ende, aquí sólo buscamos algunas líneas específicas que muestre el impacto que esta concepción de derecho tiene en la justificación de la decisión judicial. Continuando con Atienza, este autor señala algunos autores a los que en sentido estricto cabría calificar de "postpositivistas", como Dworkin, Nino o Alexy, quienes consideran que el positivismo jurídico no es ya una concepción adecuada del Derecho, sin caer por ello en formas de iusnaturalismo (Atienza, 2013, pp. 28-29).

El postpositivismo defiende la idea de que el derecho no puede verse como una realidad ya dada, o como el producto de una autoridad (es decir, de una voluntad), sino, fundamentalmente, como una práctica social que incorpora una pretensión de corrección 0 de justificación (Atienza, 2013, p. 29). El impacto que esto tiene para la justificación de la decisión es grande, ya que los operadores del derecho ahora cuentan con elementos descriptivos y prescriptivos para dotar de contenido material a los derechos fundamentales. En esta línea de argumentación, los juristas prácticos al interpretar la ley conforme a la Constitución deben asumir el fundamento formal y moral del derecho para que puedan satisfacer los fines y valores que dan sentido y legitimidad a la praxis forense. Pero, esta tarea interpretativa/ aplicativa no se debe llevar a cabo de modo imprudente ignorando los valores constitucionales, sino que el jurista postpositivista debe lograr el equilibrio entre la dimensión autoritativa del derecho con el orden de valores expresados en los principios constitucionales.

El postpositivismo constitucionalista supone una mayor demanda de justificación, de argumentación, en el derecho: tanto en términos cuantitativos como cualitativos. Y lleva a que el razonamiento jurídico no pueda configurarse como un razonamiento "insular": La argumentación jurídica tiene, necesariamente, un componente moral y político, pero ello no implica desconocer sus peculiaridades: la unidad de la razón práctica no supone la confusión entre el Derecho, la moral y la política (Atienza, 2013, pp. 29-30).

De lo anterior se colige que, tanto el neoconstitucionalismo como el postpositivismo, constituyen un nuevo modo de comprender y aplicar el derecho. Ambos asumen como presupuestos de su argumentación jurídica el modelo de los principios, de las relaciones de justificación y 
el de la ponderación; la distinción entre casos fáciles y casos difíciles, el discurso reconstructivo del derecho mismo y la concepción del derecho como práctica (Aguiló Regla, 2007). Las diferencias que suele atribuirse a estas concepciones de derecho son las siguientes: En primer lugar, el neoconstitucionalismo sólo adopta el modelo de principios, lo cual, le lleva a un mayor grado de activismo judicial; por el contrario, el postpositivismo adopta el modelo de los principios y las reglas. En segundo lugar, al neoconstitucionalismo se le atribuyen rasgos del iusnaturalismo, lo que no sucede con el postpositivismo. A nuestro juicio, independientemente de ello, ambos han superado el positivismo jurídico y han impactado positivamente en la justificación de la decisión judicial, al incorporar en el razonamiento judicial el fundamento formal y moral del derecho.

Llegado a este punto del análisis, procedemos a señalar algunos aspectos para nosotros importantes a los fines de este trabajo y para contribuir al sano debate con estas concepciones del derecho. Tenemos que reconocer que ambas contienen elementos imprescindibles para la teoría y práctica del derecho.
Sin embargo, no se deben recibir acríticamente, especialmente por las especificidades de los problemas que pretenden resolver. Como se dijo, estas concepciones del derecho nacieron en Europa para resolver los problemas de los europeos, que no son los problemas de los latinoamericanos: los europeos no han sufrido la colonización (económica, política y cultural), por el contrario, han disfrutado de un estado de bienestar que nosotros no hemos llevado a la práctica. A esto hay que agregar la falta de democracia en todas las instituciones, el impacto negativo de la actual estrategia de globalización capitalista en la esfera de los derechos sociales o derechos de emancipación, y las relaciones sociales y relaciones de fuerza que se producen en sociedades divididas y conflictivas como las latinoamericanas. Por tanto, sin prescindir de los aportes de estas concepciones del derecho, el pensamiento crítico jurídico en su versión pluralista e intercultural aporta la racionalidad reproductiva, el sujeto libre, el sentido deóntico, ideológico ${ }^{15}$ y axiológico del derecho para desarrollar un enfoque argumentativo del Derecho, que nos permita comprender y superar la inefectividad actual de los derechos fundamentales.

\title{
4. La complejidad de la racionalidad en la decisión judicial
}

\author{
Puesto en práctica el exigencia de justificación de las \\ paradigma constitucionalista, la decisiones judiciales es mayor.
}


A partir de este paradigma, los jueces en su praxis forense no deben limitarse a realizar asépticos silogismos y meras subsunciones, ya que la aplicación de la lógica formal en el razonamiento jurídico dejó de ser suficiente para dar cuenta del contenido material de los derechos fundamentales. Como vemos, esta forma de razonamiento, de tener un valor principal en la exegesis judicial, pasó a ocupar una labor puramente auxiliar; en nuestra opinión, esto tiene sentido si asumimos la tesis que la argumentación jurídica implica, sobre todo, dar razones de la objetividad de los valores o principios a ser aplicados al caso concreto, y cuyo resultado no se obtiene sólo desde elementos lógicos. En suma, el paradigma constitucionalista marcó el tránsito de un razonamiento lógico formal hacia un "razonamiento práctico-jurídico, que se realiza siempre sobre un trasfondo de normas práctico-morales, en el seno de una determinada ética vivida colectivamente, con independencia que se piense que quepa 0 no someter dicho trasfondo valorativo de todo razonamiento práctico al test de una racionalidad universal" (García Amado, 2004, pp. 110).

En este contexto, la racionalidad de la decisión judicial es un proceso complejo, pues los operadores del derecho, haciendo uso del criterio de proporcionalidad y ponderación, valoran motivadamente los principios o valores constitucionales y optan por la decisión que proteja ampliamente los derechos fundamentales, ya que la mirada de la comunidad jurídica y la comunidad política está puesta en ellos en cuanto al modo en que motivan sus resoluciones. Ahora se trata de que el jurista práctico convenza a las partes en conflicto y a su auditorio externo al proceso judicial de que aplicó de mejor modo las normas que hacen justicia al caso. Tarea que no es fácil, porque el razonamiento judicial no depende sólo de la racionalidad legislativa, sino que también depende de un razonamiento práctico conectado a lo social, cultural, histórico y la personalidad del juez.

Sin embargo, para que la decisión judicial sea razonable, los jueces deben contar, entre otras cosas, con una buena teoría de interpretación constitucional y una buena teoría de la argumentación jurídica que les permita alcanzar la compatibilidad entre el discurso de aplicación de la norma y la búsqueda de una solución justa al caso concreto. Obviamente "no se trata de convencer a los sujetos de derecho o a un auditorio de que se aplica al conflicto una buena norma, sino que se aplica del mejor modo la norma que hace justicia al caso" (García Amado, 2004, pp. 114).

En esta línea de pensamiento, las teorías de la argumentación jurídica juegan un papel importante en la justificación de la decisión 
judicial, ya que, entre otras cosas, proporciona a los jueces reglas para justificar y limitar el proceder argumentativo de la praxis forense. A partir de aquí el juzgador estará en condiciones de preguntarse: ¿Bajo qué criterios se mide la racionalidad de su decisión judicial? ¿Qué fines o valores constitucionales el discurso racional pretende realizar? ¿Qué instrumental analítico y crítico, métodos 0 argumentos utilizará en su sentencia? Como vemos, el proceso argumentativo y de razonamiento jurídico es mucho más complejo del que se practicó en el Estado legal de Derecho. Tanto las premisas normativas, el sustrato fáctico de la pretensión y los valores constitucionales son, a su vez, el resultado de sendos razonamientos que se estructuran desde el método analítico,"pues significa que sólo si se parte de un esquema suficientemente complejo y realista del razonamiento decisorio y sus etapas se tendrá el criterio para poder determinar en qué pasos y afirmaciones se ha de ser especialmente exigente en la justificación argumentativa" (García Amado, 2004, pp. 118).

Del párrafo anterior se colige que la complejidad de la racionalidad de la decisión judicial está, en cierta forma, condicionada por la concepción de derecho que asume el juzgador para argumentar e interpretar el derecho. Pues, tal como Jaime Cárdenas Gracia señala, no sólo el modelo de derecho impacta en los modos de argumentar; también el tipo de sociedad y cultura en donde se implanta el derecho determina en buena medida su concepción. "La argumentación en sociedades democráticas, pluralistas y heterogéneas tiene una connotación muy distinta a la de las sociedades autoritarias, no pluralistas y homogéneas. La argumentación también es determinada por las orientaciones en favor de las minorías y presencia de fenómenos como la globalización. Sin duda, los niveles de desarrollo y el momento histórico generan comprensiones propias sobre el derecho y la argumentación" (Cárdenas Gracia, 2007, pp. 38-97).

Llegado a este punto del análisis, cabe preguntarse si para sociedades divididas y conflictivas como las latinoamericanas basta la crítica que Atienza hace a la teoría estándar de la argumentación jurídica ${ }^{16}$ y su propuesta de teoría alternativa, - será necesario que los jueces interpreten el Derecho y justifiquen su decisión judicial desde una racionalidad mucho más compleja. En nuestra opinión, es necesario que la teoría de argumentación jurídica que adopten no se limite sólo al contexto de justificación, sino que también se extienda al contexto de descubrimiento, es decir, que no bastan las razones que justifican la decisión judicial, también es necesario que la argumentación exija tomar en cuenta factores de tipo 
económico, psicológico, ideológico, etc. Especialmente, en el contexto actual de globalización económica, donde el capital,"además de invadirlo todo, lo sobredetermina todo, se apodera de esos ámbitos, de sus elementos materiales, pero también de sus conceptos y categorías y los funcionaliza, los convierte en medios adecuados a su continua producción y reproducción como sistema social" (Cabo Martín, 2014 p. 62).

Ahora bien, hay dos elementos de la propuesta de Atienza a los que llama teoría alternativa de la argumentación jurídica, y que nos interesan para los fines de este apartado. El primero de ellos consiste en contar con una teoría de la argumentación jurídica que comprenda no solo los razonamientos que se producen en la interpretación y aplicación del derecho, sino de la argumentación que tiene lugar en el ámbito de la producción del derecho. El jurista práctico, para justificar bajo la idea de corrección la decisión judicial, no solamente debe asegurar los precedentes judiciales, sino que también debe enjuiciar críticamente la racionalidad de la ley, máxime cuando su pretensión radica en el hecho de concretizar fines y valores constitucionalmente reconocidos. En esa medida, el juzgador deberá ponderar la necesidad e idoneidad de la medida que adoptó el legislador para defensa de los derechos fundamentales. Como vemos, bajo este esquema metodológico es necesario operar con un modelo complejo de racionalidad práctica, que combine la racionalidad discursiva con la racionalidad estratégica; asimismo, la racionalidad discursiva con la racionalidad teleológica. Es decir, que el jurista práctico debe observar si la ley está precedida de la negociación y el consenso para resolver un conflicto social; asimismo, debe dilucidar si la acción estratégica entre sujetos, al ser combinada con la racionalidad teleológica conlleva a la elección de medios idóneos para lograr fines y valores que posibiliten el desarrollo de la personalidad de todos los sujetos de derecho.

El segundo elemento se refiere al hecho de que la teoría de la argumentación jurídica no puede tener un carácter puramente prescriptivo, sino que ha de ser también descriptiva; con ello quiero decir que debe ser capaz de dar cuenta suficientemente de los argumentos que tienen lugar de hecho en la vida jurídica. Esto puede entenderse, a su vez, en dos sentidos. Se necesita contar, no solo con criterios sobre cómo se argumentó la decisión judicial para que sea aceptada por su auditorio, sino también de un método que permita descubrir cómo se fundamentan de hecho las decisiones tomadas. Dicho de otra manera, tanto en el contexto de descubrimiento como en el contexto de justificación se puede llevar a cabo un tipo de discurso 
doble: descriptivo y prescriptivo (Atienza, 2005, pp. 205-207).

El aporte de Manuel Atienza es importante para abordar con seriedad el problema de la racionalidad de la decisión judicial en América Latina, pero debe ser complementado con otros factores en juego a la hora de justificar la decisión judicial. Como dice Manuel Segura Ortega: "En el proceso que conduce a la decisión hemos encontrado una serie de elementos que escapan a toda previsión normativa, pero que influyen en el contenido de la resolución final; la personalidad del juez ${ }^{17}$, la exigencia de ciertos valores y expectativas que están presentes en el seno de los grupos sociales, determinadas concepciones ética y políticas, etc. Todo hace que el proceso decisorio no sea un camino fácil, sino que, por el contrario, esté lleno de obstáculos y dificultades de toda índole" (Segura Ortega, 2998, p. 115). A esto hay que agregar, la independencia o dependencia judicial, el modo de elección, la vocación de poder o vocación de servicio que tenga el juzgador, etc. Por tanto, en la medida que estos factores o elementos no pueden ser controlados de modo eficaz o permanecen ocultos, la decisión judicial adolecerá de un déficit de razonabilidad.

Por otro lado, una racionalidad compleja de la decisión judicial debe abrir un debate serio sobre la idea de corrección de la decisión, pues, como se viene diciendo, el hecho de que se cumplan las condiciones del discurso racional no garantiza la corrección del resultado, ya que puede resultar que las reglas que se siguen para el discurso racional sean deficientes, o bien porque se actúa bajo la creencia que el Estado Constitucional de Derecho vigente es el mejor de todos los posibles, sin decir por qué y sin justificarlo. En suma, no basta creer que porque las sociedades contemporáneas se rigen por el multiculturalismo moral o el relativismo ético la idea de corrección funcional está garantizada; al contrario, "la racionalidad alcanzable para la decisión es siempre relativa a un contexto histórico social determinado" (Segura Ortega, 1998, p.125). Por ende, ante la complejidad de la racionalidad de la decisión, esta debe ser provisoria, y su justificación tiene que ser siempre parcial y revisable.

Al cierre de este apartado, reiteramos nuevamente que tanto en la teoría y en la praxis forense existen grandes aportes en materia de argumentación jurídica que discurren en argumentación formal, material y pragmática, pero frente a nuestra realidad de exclusión, marginación social, falta de democracia y falta de autonomía. Se necesita elaborar una teoría que proporcione criterios firmes para justificar y evaluar las decisiones. Máxime porque, en sociedades como la nuestra, el criterio de vida o muerte se convierte en el criterio de última instancia. Por tanto, la 
complejidad de la racionalidad de la decisión judicial exige una integración de racionalidades, que pasa por la racionalidad medio-fin, racionalidad comunicativa, racionalidad estratégica, pero todas ellas subordinadas a la racionalidad reproductiva, ya que esta última se enfrenta a la pretensión de mostrar como racionales las acciones que producen muerte.

\section{Algunas propuestas de solución a considerar}

Hecho el diagnóstico situacional en esta crítica propositiva efectuada, es hora de formular algunas propuestas viables y factibles. Partiendo de la premisa de contar con un diagnóstico modestamente acertado del problema resentido en materia de racionalidad de la decisión judicial en Latinoamérica y en nuestro país, toca detectar a fondo tanto las falencias estructurales y las coyunturales, como también las exigencias de justicia a cubrir en cada caso. Aquí, la interrogante clave es: ¿Qué debemos hacer los juristas prácticos para que la justificación de la decisión judicial reproduzca la vida digna de todos y todas?

Desde luego que la respuesta no es nada sencilla, aunque lo único que en realidad se requiere para actuar es la voluntad de cambio, terminando por entender al menos lo básico: los criterios firmes para justificar y evaluar las decisiones judiciales requieren de creatividad, compromiso ético y la participación de todos los afectados de la sociedad, no para alcanzar la estandarización de la justificación de las sentencias en este tipo de asuntos tan polarizados, sino más bien para construir los consensos necesarios para la reproducción, defensa y desarrollo de la vida digna de todos y todas. Por razones de espacio sólo abordaré brevemente tres propuestas a considerar.

A. La crítica a la inversión ideológica ${ }^{18}$ como criterio hermenéutico para evaluar el universalismo abstracto y la absolutización de los derechos humanos occidentales. Se trata una herramienta hermenéutica importante para que los juristas prácticos lleguen a una mejor comprensión de los problemas reales, posibilidades y límites del derecho; por tanto, al momento de elucidar la inversión de los derechos humanos, se debe incorporar en términos estrictamente teóricos, al acto de interpretación y aplicación de la ley; específicamente como dispositivo crítico-evaluativo para cuestionar las leyes, ya sea enjuiciándolas o evidenciando que la inversión de los derechos humanos se activa cuando se articula el desequilibrio de intereses entre 
los sujetos de derecho, los cuales cuando se normalizan tienden a absolutizarse sobre la base de la exclusión de cualquier otra alternativa posible.

B. Propuesta de la ética de la convivencia. La ética de la convivencia no es una ética de normas, aunque implique normas. De hecho, las normas importantes no están en cuestión (no matarás, no robarás, no engañarás, etc.), pueden ser divinas o normas de bandas de ladrones. También las bandas de ladrones las tienen en su interior (Hinkelammert, 2012, p. 183). Por ello, lo importante para la ética de la convivencia no es el cumplimiento de las normas, sino que las normas tengan la convivencia social como criterio principal y final de la interpretación y aplicación de la ley. Se trata de descartar de la praxis forense el principio: "Yo soy si te derroto a ti" y sustituirlo por el principio: "No se puede vivir sino vive el Otro", hacer lo contrario significa el suicidio colectivo y, por ende, la no defensa de la vida digna de todos.

C. En el plano de la filosofía del derecho, se debe dar el salto de la racionalidad instrumental hacia la racionalidad reproductiva. A nuestro juicio, esta última aporta un criterio elemental y central para la comprensión, interpretación y aplicación del derecho en función de la reproducción de la vida digna de todos. Ahora bien, esto no significa que la racionalidad reproductiva deba eliminar la racionalidad medio-fin. Más bien, de lo que se trata, es de aplicar un juicio de compatibilidad entre las dos racionalidades, en donde la racionalidad reproductiva juzga sobre la racionalidad medio-fin, y en caso de contradicción ésta última se subordina a la primera, es decir, los criterios técnicos pasan a ocupar un lugar secundario, y la primariedad la tendrá el criterio material de la reproducción de la vida digna de todos y todas. Como vemos, la racionalidad mediofin hace la selección técnica de los fines expresados en normas, procedimientos, reglas, valores. Pero eso no basta. Hace falta ver la condición de posibilidad de cada uno de esos fines para constatar si estos conducen a la reproducción de la vida de todos los seres humanos o a la destrucción de los necesitados y vulnerables. A este criterio material de la reproducción de la vida como última instancia de posibilidad y factibilidad del sistema de derecho de derecho, Franz Hinkelammert lo considera parte de la racionalidad reproductiva, pues, la reproducción de la vida humana actúa como condición de última instancia, como el objetivo último y la primera condición de existencia del sistema como 
un todo" (HInkelammert y Mora, 2008, pp. 186-187).

En conclusión, y parafraseando la tesis I sobre el concepto de historia de Walter Benjamin, el pensamiento crítico jurídico es el enano jorobado que nadie quiere ver, pero que asegura la partida, siempre y cuando sea autocrítico, provisional, contextual, transformador, descolonizador y dialógico. Por tanto, es consciente que no tiene todas las respuestas a los problemas teóricos y prácticos del derecho, y en esa medida entra en diálogo con las concepciones del derecho convencional para hacer presente lo que está ausente: la reproducción de la vida digna de todos y todas.

La idea de fondo es propiciar las condiciones jurídico-políticas para la construcción de una sociedad donde todos quepan y refundar el Estado social de derecho. En eso consiste el actual desafío y mayor reto que enfrentamos ahora. La clave está en hacer presente lo que es imposible, pues de lo imposible surge lo posible.

\section{Referencias bibliográficas}

- Aguiló Regla, J. (2007). Positivismo y postpositivismo. Dos paradigmas jurídicos en pocas palabras. Doxa: Cuadernos de filosofía del derecho. 30, pp. 665-675. Recuperado de:http://www.cervantesvirtual.com/descargaPdf/positivismo-y-postpositivismo-dos-paradigmas-juridicos-en-pocaspalabras--0/

- Alexy, R. (2008) Teoría de los derechos fundamentales. Madrid: Centro de Estudios Políticos Constitucionales.

- Atienza, M. (2007). Una propuesta de filosofía del derecho para el mundo latino. Doxa: Cuadernos de filosofía del derecho. 30,pp.661-663. Recuperado de: http://www.cervantesvirtual.com/descargaPdf/una-propuesta-defilosofia-del-derecho-para-el-mundo-latino--0/

- Atienza, M. (2012). El derecho como argumentación. Barcelona: Ariel.

- Atienza, M. (2005). Las razones del derecho. México: UNAM.

- Bernal Pulido, C. (1989). Estructura y límites de la ponderación. Doxa. Cuadernos de filosofía del derecho. 26, pp 225-238. Recuperado de: http:// www.cervantesvirtual.com/nd/ark:/59851/bmc1v5t1

- Cárcova, C. M. (2009). Las teorías jurídicas post positivistas. Buenos Aires: Abelardo Perrot.

- Cárdenas Gracia, J. (2007), La argumentación como derecho. México: UNAM. 
- Cabo Martín, C. (2014). Pensamiento crítico, constitucionalismo crítico. Madrid:Trotta.

- Duchrow, U. y Hinkelammert, F. J. (2003). La vida o el capital. San José: DEI.

- Dussel, E. (2009). Política de la liberación (II). Madrid: Trotta.

- Facio, A. (1999). Hacia otra teoría crítica del derecho. En Fries, L. y Facio A. (comps.) Género y derecho. Santiago: Lom Ediciones, La Morada. Disponible en: http://www.flacso.org.ec/docs/safisfacio.pdf

- Fernández, E. y Vergara,J. (Eds.) (2006). Racionalidad, utopía y modernidad. El pensamiento crítico de Franz Hinkelammert. Santiago: Editorial Universidad Bolivariana.

- Ferrajoli, L. (2014). La democracia a través de los derechos. Madrid: Trotta.

- García Amado, J. A. (2004). Interpretación y argumentación jurídica. Guías de estudio elaborada por Lizama, S. A. San Salvador: Consejo Nacional de la Judicatura.

- García Figueroa, A. (2009). Criaturas de la moralidad. Una aproximación neoconstitucionalista al derecho a través de los derechos. Madrid: Trotta.

- Hinkelammert, F. (1990). Democracia y totalitarismo. DEI: San José.

- Hinkelammert, F. (2000). La fe de Abraham y el Edipo occidental. DEI: San José.

- Hinkelammert, F. (2003). El asalto al poder mundial y la violencia sagrada del imperio. DEl: San José.

- Hinkelammert, F. (2005). El sujeto y la ley. Heredia: Editorial Universidad Nacional.

- Hinkelammert, F. (2007). Hacia una crítica de la razón mítica. El laberinto de la modernidad. San José: Editorial Arlekín.

- Hinkelammert, F. (2008). Sobre la reconstitución del pensamiento crítico. Realidad. Revista de Ciencias Sociales y Humanidades. 115 (pp. 35-64). San Salvador: Universidad Centroamericana "José Simeón Cañas".

- Hinkelammert, F. (2010). La maldición que pesa sobre la ley. Las raíces del pensamiento crítico en Pablo de Tarso. San José: Arlekín.

- Hinkelammert, F. (2012). Lo indispensable es inútil. Hacia una espiritualidad de la liberación. San José: Arlekín.

- Hinkelammert, F. y Mora Jiménez, H. (2008). Hacia una economía para la vida. San José: Instituto Tecnológico de Costa Rica. 
- Hinkelammert, F. (Ed.) (2017). La religión neoliberal del mercado y los Derechos Humanos. San José: Arlekín.

- Hinkelammert, Franz y Mora Jiménez, Henry. Hacia una economía para la vida, Segunda edición, Editorial tecnológica de Costa Rica, 2008.

- Lifante Vidal, I. (2008). La interpretación jurídica y el paradigma constitucionalista. Recuperado de: https://boe.es/publicaciones/anuarios_derecho/ abrir_pdf.php?id=ANU-F-2008-10025700278

- Martínez Dalmau, R.y Viciano Pastor,R.(2011). Fundamentos teóricos y prácticos del nuevo constitucionalismo latinoamericano. Gaceta Constitucional. 48, pp. 307-328.

- Meliante Garcé, L.(2014). La crítica jurídica latinoamericana: de la invisibilidad a su consideración en la doctrina nacional. Revista de la Facultad de Derecho, Universidad de la República. 36, pp. 153-183.

- Molina Velásquez, C. (2006). El sujeto viviente y la ética del bien común. El pensamiento ético de Franz Hinkelammert. (Tesis doctoral). San Salvador: Universidad Centroamericana “José Simeón Cañas".

- Molina Velásquez, C. (2017). Pluralismo moral y relativismo ético. Revista Redbioética/UNESCO. 1. (15). Pp. 91-105.

- Núñez Vaquero, A. (2009), Teorías críticas del derecho: observaciones sobre el modelo de ciencia jurídica. Recuperado de: https://boe.es/publicaciones/ anuarios_derecho/abrir_pdf.php?id=ANU-F-2010-10041300434

- Pozzolo, S. (1998). Neoconstitucionalismo y especificidad de la interpretación constitucional. Doxa. 2. (21), pp. 339-353. Recuperado de: http:// www.cervantesvirtual.com/descargaPdf/neoconstitucionalismo-y-especificidad-de-la-interpretacin-0/

- Rosillo Martínez, A. (2009). El pensamiento jurídico de Ignacio Ellacuría. Hacia la construcción de una teoría crítica de derechos humanos. Revista Latinoamericana de Teología (78), pp. 255-278.

- Sala de lo Constitucional. Sentencia 1-III-2013, Inc. 78-2011.

- Santos, B. de S. (2003). Crítica de la razón indolente. Bilbao: Desclée de Brouwer.

- Sandoval Cervantes, D. (2015). El constitucionalismo en América Latina desde una perspectiva histórica crítica del derecho. En: Wolkmer, A. C. y Lixa, I. F., (Orgs.). Constitucionalismo, descolonización y pluralismo jurídico en América Latina. Aguascalientes: CENEJUS, pp. 103-115.

- Segura Ortega, M. (1998), Racionalidad jurídica. Madrid: Tecnos. 
- Solórzano Alfaro, N. (2007). Crítica de la imaginación jurídica. Una mirada desde la epistemología y la historia al derecho moderno y su ciencia. (Tesis doctoral). San Luis Potosí: Universidad Autónoma de San Luis Potosí.

- Wolkmer, A. C. (2003). Pluralismo jurídico. Fundamentos de una nueva cultura del Derecho. Sevilla: Editorial Mad.

- Wolkmer, A. C. (2006). Introducción al pensamiento jurídico crítico. San Luis Potosí: Universidad Autónoma de San Luis Potosí.

- Wolkmer, A. C. y Lixa, I. F., (Orgs.). (2015). Constitucionalismo, descolonización y pluralismo jurídico en América Latina. Aguascalientes: CENEJUS.

\section{Notas}

1. Hinkelammert y Mora (2008), siguiendo la ética del sujeto de Karl Marx, reivindican la supremacía del sujeto sobre las instituciones, y en esa medida, señalan: "El ser humano en cuanto sujeto es el criterio de juicio sobre todas las leyes y las instituciones" (2008, p. 468).

2. Núñez Vaquero (2009), siguiendo a Luigi Ferrajoli, sostiene: "Las propuestas de la ciencia jurídica crítica que invitan al jurista a intentar modificar las interpretaciones acogidas por la sociedad y por los tribunales, si bien pueden tener a su favor importantes razones materiales de fondo, cargan con un importante déficit de legitimidad al convertirse en una ulterior instancia de decisión no justificada democráticamente".

3. Hinkelammert y Mora Jiménez (2008) indican: "El respeto primario por los derechos humanos no es ya un mero deseo romántico, sino la condición de posibilidad (exigencia) de la propia sobrevivencia humana" (2008, p. 478).

4. Atienza (2007), al reflexionar sobre la importancia de las teorías críticas del derecho, nos muestra "la necesidad de que la teoría del Derecho incorpore ciertas categorías que generalmente quedan fuera del análisis...asuma el carácter histórico del derecho y de las categorías jurídicas y preste atención a los elementos desigualitarios e ideológicos del derecho (también de los derechos del Estado Constitucional".

5. Los obstáculos epistemológicos son aquellos que generan estancamientos y retrocesos, confusiones y estancamientos en el conocimiento y en la praxis.

6. Este sociólogo del derecho define ambas formas de cocimiento del siguiente modo: "El conocimiento-emancipación consiste en una trayectoria que va desde un estado de ignorancia que designo como colonialismo, a un estado de saber que designo como solidaridad. $A$ contrario sensu, el conocimiento-regulación consiste en una trayectoria que va desde un estado de ignorancia que designo como caos, a un estado de saber que designo como orden" (87).

7. El filósofo alemán parte de la idea que, bajo la estrategia de globalización capitalista, las burocracias privadas se han tomado el poder en nombre de la democracia y de los derechos humanos, al grado, que los derechos humanos del ser humano declarados a partir de la ciudadanía, pierden su vigencia.

8. Atienza (2005, p. 206) habla de racionalidad lingüística, racionalidad jurídicoformal, racionalidad pragmática, racionalidad teleológica, y racionalidad ética. A estos tipos de racionalidad agrega- 
ríamos la racionalidad reproductiva que propone Franz Hinkelammert.

9. Al analizar Rosillo Martínez (2009) el pensamiento jurídico de Ignacio Ellacuría y la tradición hispanoamericana de los derechos humanos, señala que América Latina puede hablar de derechos humanos sin asumir forzosamente sus matrices eurocéntrica, monocultural, individualista y burguesa, ya que desde sus propias circunstancias sociohistóricas, la lucha por la dignidad ha adquirido un sentido pluricéntrico, pluricultural, comunitario y popular, que hace evidente, que las tradiciones noratlánticas (inglesa, francesa y estadounidense) no pueden considerarse como las únicas defensoras y promotoras de derechos humanos.

10. El pensamiento crítico jurídico a la hora de construir su teoría sobre el sujeto concreto de derecho no debe cerrar sus oídos a la crítica que se hace desde el feminismo al derecho, específicamente sobre la configuración actual del sujeto de derecho, el cual en palabras de Alda Facio, "es el hombre adulto, adinerado, sin discapacidades visibles, heterosexual y perteneciente a la raza, etnia, clase y religión dominante en cada cultura". (Facio, 1999, p 20).

11. A propósito de la definición del formalismo jurídico han corrido ríos de tinta en la filosofía del derecho, pero para ser congruentes con esta investigación, Manuel Atienza dice al respecto: "para el formalismo jurídico el Derecho moderno consiste en buena medida en una serie de reglas preexistentes al aplicador, de manera que la toma de decisiones jurídicas, salvo en supuestos marginales, no exige propiamente una deliberación y resulta así relativamente previsible". (Atienza, 2012, pp. 22-23).

12. "La primera tesis del positivismo jurídico es la separación entre derecho y moral. El derecho se define no por su moralidad, sino en función de su vinculación a la organización del uso de la fuerza. El derecho es producto de una convención, de un acto de voluntad". (Cárdenas, 2007, p. 48).

13. Respecto al postulado positivista de la discrecionalidad Jaime Cárdenas al reflexionar sobre el neoconstitucionalismo señala: "La discrecionalidad es controlada, no con una herramienta falsa e inadecuada - la subsunción y el silogismo- para todos los casos, sino con argumentos diferentes que signifiquen un mayor esfuerzo justificatorio, como es el caso del uso del principio de proporcionalidad". (Cárdenas, 2007, p. 43).

14. Susanna Pozzolo, hablando del neoconstitucionalismo afirma: "Si bien cierto que la tesis sobre la especificidad de la interpretación constitucional encuentra partidarios en diversas disciplinas, en el ámbito de la filosofía del derecho viene defendida, en particular, por un grupo de iusfilósofos que comparten un modo peculiar de acercarse al derecho. He llamado a tal corriente de pensamiento neoconstitucionalismo. Me refiero, en particular, a autores como Ronald Dworkin, Robert Alexy, Gustavo Zagrebelsky y, sólo en parte, Carlos S. Nino". (Pozzolo, 1998).

15. Daniel Sandoval Cervantes, al reflexionar sobre el derecho desde una perspectiva de la historia crítica, afirma que la constitucionalización del derecho contiene un sentido deóntico y un sentido ideológico. El sentido deóntico, añade, es aquél que expresa en forma de norma jurídica las reivindicaciones de los movimientos sociales. El sentido ideológico, según este autor, consiste en naturalizar las desigualdades inherentes al capital, principalmente la concentración de los medios de producción y la distinción entre quién está en condiciones de mandar y quiénes en las de, simplemente, obedecer. Así que, para justificar la decisión judicial bajo una pretensión de corrección y justicia, los operadores del derecho deben comprender las relaciones de fuerza, las relaciones 
sociales desde las cuales se constitucionalizan los derechos, y desde las cuales los sujetos de derecho utilizan dichos textos y tratan de definir sus contenidos aplicables a la vida concreta. (Sandoval Cervantes, 2015).

16. Con relación a la teoría estándar de la argumentación jurídica, Atienza señala que: es insuficiente en cuanto que: descuidan a no tratan en absoluto aspectos muy importantes del razonamiento jurídico; no ofrecen un método que permita, por un lado, analizar adecuadamente los procesos de argumentación jurídica y, por otro lado, evaluar los resultados de los mismos; y tienen un interés limitado para el teórico y práctico del derecho, al punto que resultan insuficientemente críticas en relación con el derecho positivo, considerado tanto estática como dinámicamente". Atienza, 2005, p. 204).

17. Como decía Ross citado por Segura Ortega: "El juez es un ser humano. Detrás de la decisión que adopta se encuentra toda su personalidad. Por eso, nunca puede actuar al margen de dicha personalidad: su formación, educación, creencias, ideología, etc., le acompañan siempre". (Segura Ortega, 1998, p. 105).

18. En la crítica de Franz Hinkelammert al paradigma liberal de los derechos humanos se denuncia el método de "inversión ideológica de estos derechos", el cual consiste el cual consiste en violar los derechos humanos en nombre de su cumplimiento. (Hinkelammert, 2007, p. 232). 
